\title{
Status of primitive bronchopulmonary cancers in the Sylvanus Olympia Chu pneumology sevice (Togo)
}

\begin{abstract}
In Africa, primary bronchial cancer appears to be a rare disease, unlike developed countries, where it is a real public health problem. This work reviews the epidemiological, clinical and therapeutic outcome over 5 years of patients followed for primary bronchopulmonary cancers (CBPP). This was a five-year retrospective study of inpatient and follow-up records for CBPP. Out of 389 bronchial fibroscopies performed in 5 years, 26 cases $(6.68 \%)$ of CBPP were collected and were the subject of our study. 5 male patients $(20.83 \%)$ out of 24 reportedly smoked, the remaining two lacked sufficient history. The predominant functional signs were chest pain and cough in $76.92 \%$ of cases. In $34.61 \%$ of the cases, pleurisy was associated. The clear majority (68.41\%) of patients consulted late: stage III (15.78\%); stage IV (52.63\%), endoscopic lesions were mainly buds in $26.08 \%$ of the cases. The anatomic-pathological examination of the bronchial biopsies, found $30.76 \%$ of epidermoid carcinoma, $26.92 \%$ of small cell cancer and $15.38 \%$ of adenocarcinoma. Treatment was mainly palliative care $(88.46 \%)$ with $11.53 \%$ receiving chemotherapy. Increased tobacco control, the existence of thoracic surgery and multidisciplinary consultation meetings are needed to better manage CBPP in the service.
\end{abstract}

Volume 5 Issue I - 2018
Assao Neino MM,' Adjoh S, ${ }^{2}$ Gagara IMA,' Adambounou TAS, ${ }^{2}$ Ouedraogo $A R,{ }^{2}$ Okemba Okombi $\mathrm{FH},{ }^{2}$ Fiogbe AA, ${ }^{2}$ Alfazazi $\mathrm{S},{ }^{2}$ Bako $\mathrm{M},{ }^{2}$ Maizoumbou DA,' Tidjani $\mathrm{O}^{2}$

'Pneumo-Phthisiology Department, Lamordé National Hospital, Niger

${ }^{2}$ Sylvanus Olympio CHU Respiratory Department, Niger

Correspondence: Assao Neino MM, Pneumo-Phthisiology Department, Lamordé National Hospital, Niamey, Niger, Emailmourt2000@yahoo.fr

Received: September 17, 2017| Published: February 19, 2018

Keywords: primary bronchopulmonary cancer, frequency, Togo

\section{Introduction}

Bronchopulmonary cancers (CBP) are malignant tumors developed at the expense of bronchial and/or parenchymal structures. They may be secondary or primitive. The latter are the leading cause of cancer mortality in developed countries. Several studies show that this cancer will be the leading cause of cancer death in women in France around 2020. ${ }^{1}$ In Africa, primary bronchial cancer appears to be a rare disease, unlike the developed countries, where it is a real public health problem. ${ }^{2}$ The positive diagnosis of primary bronchopulmonary cancer is based on the association of: an evocative, nonspecific clinical symptomatology often neglected by the patient, suspicious thoracic imaging and histological evidence obtained by biopsy (bronchus, puncture transthoracic, pleural and lymph node biopsy). ${ }^{3}$ Since 1960 , bronchial fibroscopy has been practiced in industrialized countries. ${ }^{4}$ In developing countries, the financial constraints inherent in this technique mean that few respiratory services have the necessary equipment to perform bronchial endoscopies. ${ }^{5}$ In Togo, there are no thoracic surgeons and 52 cases of bronchopulmonary cancers were observed from 1982 to 1987 at CHU Sylvanus Olympio in Lomé on 275 bronchial fibroscopies, ie $18.9 \%{ }^{6}$ This led us to carry out this work, the aim of which is to take stock of primary bronchopulmonary cancers at the CHU Sylvanus Olympio, in the Infectious Diseases and Pneumology Department (SMIP).

\section{Materials and methods}

Our five-year retrospective study examined inpatient or outpatient records for primary bronchopulmonary cancers from January 1, 2007 to December 31, 2012 inclusive. The Laboratory of AnatomyCytopathology (LACP) and the Department of Infectious Diseases and Pneumophysiology (SMIP) of the CHU Sylvanus Olympio in Lomé (Togo), which is the national reference service for the management of respiratory diseases and We have included in our study the records of patients who underwent cytological or pathological examination of the pulmonary nodule by pulmonary biopsy, adenopathy, and bronchial fibroscopy (biopsy, aspiration, brushing) and pleural biopsy. Finally, the data were collected on a survey sheet and analyzed manually.

\section{Results}

A total of 26 patients met our inclusion criteria and constituted the sample of our study, the mean age of patients was 56.65 years with extremes of 35 and 83 years. The age group between 3 and 47 years was the majority $(30.76 \%)$ of the cases. In our sample we found 19 men $(73.07 \%)$ versus 7 women $(26.93 \%)$ with a sex ratio of 2.71 men to women. The most represented occupations were $8(36.36 \%)$ civil servants. and agro-pastoral $5(22.72 \%)$ see Table 1. During the study period, 389 bronchial fibroscopies were performed in 5 years (mean annual 77.2 fibroscopies) and 26 cases of primary bronchopulmonary cancers $6.68 \%$ of all the fibroscopies performed. More than half of the patients were hospitalized (65.38\%).

Table I Distribution of cases by occupation

\begin{tabular}{ll}
\hline Occupation & Number (Percentage) \\
\hline Officer & $8(36.36 \%)$ \\
Agro & $5(22.72 \%)$ \\
Not specified & $4(18.18 \%)$ \\
Merchant & $2(9.09 \%)$ \\
Welder & $2(9.09 \%)$ \\
Auto Mechanic & $2(9.09 \%)$ \\
Masson & $\mathrm{I}(4.54 \%)$ \\
Housewife & $\mathrm{I}(4.54 \%)$ \\
Painter & $\mathrm{I}(4.54 \%)$ \\
\hline
\end{tabular}

\section{Antecedents}

Informed smoking in 24 patients out of 26 was reported in 5 patients all men, $20.83 \%$, alcohol and hypertension were the most 
frequent personal history $19.23 \%$ each. The average cigarette packyears was 12 with the extremes of 2 and 20 see Table 2.

Table 2 Distribution of cases by number of cigarette year

\begin{tabular}{ll}
\hline $\begin{array}{l}\text { Number of Package } \\
\text { Year (PA) }\end{array}$ & $\begin{array}{l}\text { Number of Employees } \\
\text { (Percentage) }\end{array}$ \\
\hline 20 packets year & $2(40 \%)$ \\
7 packets year & $\mathrm{I}(20 \%)$ \\
2 packets year & $\mathrm{I}(20 \%)$ \\
I2 packets year & $\mathrm{I}(20 \%)$ \\
Total & $5(100 \%)$ \\
\hline
\end{tabular}

\section{General and clinical signs}

The general condition was altered in 13 patients $(50 \%)$. Chest pain and cough were the most frequent functional signs $76.92 \%$, followed by slimming $65.38 \%$ see Table $3 \&$ Table 4 . Pleural pain was the most frequent associated clinical manifestation found in 9 patients (34, $61 \%)$ see Table 5. More than half of our patients $(68.41 \%)$ had seen at stage III (locally advanced $15.78 \%$ ) and stage IV (disseminated $52.63 \%$ ) see Table 6 .

Table 3 Distribution of patients by condition degradation

\begin{tabular}{ll}
\hline General Staff & Number (percentage) \\
\hline Bad & $13(50 \%)$ \\
Passable & $8(30.76 \%)$ \\
Good & $5(19.23 \%)$ \\
Total & $26(100 \%)$ \\
\hline
\end{tabular}

Table 4 Distribution of patients by functional and general signs

\begin{tabular}{ll}
\hline Functional and General Signs & Number (Percentage) \\
\hline Chest Pain & $20(76.92 \%)$ \\
Cough & $20(76.92 \%)$ \\
Slimming & $17(65.38 \%)$ \\
fever & $12(46.15 \%)$ \\
Dyspnea & $11(42.30 \%)$ \\
Hemoptysis & $5(19.23 \%)$ \\
\hline
\end{tabular}

Table 5 Distribution of cases according to the associated clinical picture

\begin{tabular}{ll}
\hline Associated Clinical Profile & Workforce (\%) \\
\hline Pleurisy & $9(34.61 \%)$ \\
Chronic obstructive pulmonary disease & $3(11.53 \%)$ \\
Acute or subacute psoriasis not suppurative & $3(11.53 \%)$ \\
\hline
\end{tabular}

\section{Additional tests}

The frontal chest $\mathrm{x}$-ray was performed in $73.07 \%$ of patients and bronchial fibroscopy was performed in 23 patients $(88.46 \%)$. Patient pleurisy was the radiographic image found in $26.31 \%$ of cases, atelectasis in $21.05 \%$ and pulmonary nodule alone in $15.78 \%$ of cases Table 7.
Table 6 Distribution of cases according to the stage of cancer

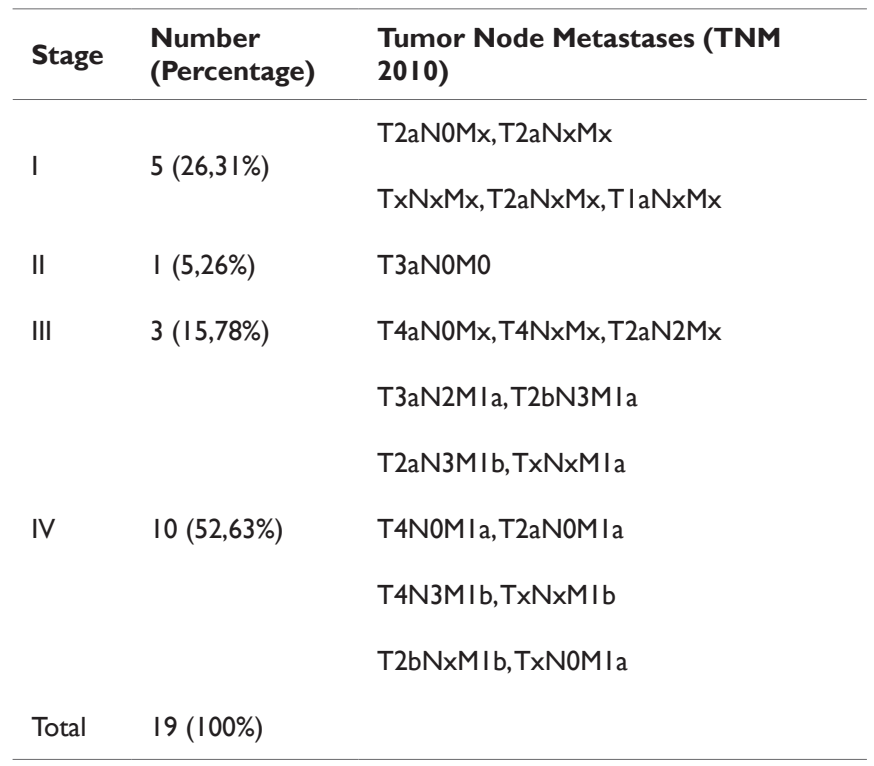

Table 7 Distribution of patients by radiological image aspect

\begin{tabular}{ll}
\hline Radiographic image & Workforce (Percent) \\
\hline Pleurisy & $5(26.31 \%)$ \\
Atelectasis & $4(21.05 \%)$ \\
Nodule unique & $3(15.78 \%)$ \\
Pleurisy + Atelectasis & $2(10.52 \%)$ \\
Alveolar condensation & $\mathrm{I}(5.26 \%)$ \\
Single nodule + Atelectasis & $\mathrm{I}(5.26 \%)$ \\
Nodule unique + Pleurisy & $\mathrm{I}(5.26 \%)$ \\
Mediastinal tumor + pleurisy & $\mathrm{I}(5.26 \%)$ \\
Mediastinal tumor & $\mathrm{I}(5.26 \%)$ \\
Total imaging realized & $\mathrm{I}(\mathrm{I})$ \\
\hline
\end{tabular}

\section{Endoscopic aspect of lesions}

Intralumenal cancerous budding lesions were observed in $26.08 \%$ of cases see Table 8 .

Table 8 Patient distribution according to the macroscopic aspect of the endoscopic lesions

\begin{tabular}{ll}
\hline $\begin{array}{l}\text { Macroscopic aspects of endoscopic } \\
\text { lesions }\end{array}$ & Number (\%) \\
\hline Budding & $6(26,08 \%)$ \\
Bronchial Stenosis & $5(21,73 \%)$ \\
Inflammatory bronchial mucosa & $5(21,73 \%)$ \\
Extrinsic Compression & $4(17,39 \%)$ \\
Thickening of the spurs & $3(13,04 \%)$ \\
\hline
\end{tabular}

\section{Histology}

The mean waiting time for the histological results was 25 days (extremes of 7 to 67 days). Squamous cell carcinoma was the most 
frequent histologic type $(30.76 \%)$, followed by small cell carcinoma $(26.92 \%)$ and adenocarcinoma (15.38\%), see Table 9.

Table 9 Distribution of patients by histologic type

\begin{tabular}{ll}
\hline Histological Type & Number (Percent) \\
\hline Carcinoma epidermoid & $8(30.76 \%)$ \\
Small cell cancer & $7(26.92 \%)$ \\
Differentiated carcinoma & $5(19.23 \%)$ \\
Adenocarcinoma & $4(15.38 \%)$ \\
Large cell carcinoma & $\mathrm{I}(3.84 \%)$ \\
Adenosquamous composite carcinoma + & $\mathrm{I}(3.84 \%)$ \\
Squamous adenocarcinoma) & $26(100 \%)$ \\
\hline Total & \\
\hline
\end{tabular}

\section{Treatment and evolution}

Palliative care was administered in 23 patients $(88.47 \%)$ and chemotherapy in 3 patients (11.53\%). There were 5 deceased patients (19.23\%), 12 (46.15\%) hospitalized and 9 (34.61\%) whose fate was not specified in Table 10 .

Table 10 Distribution of cases by fate of patient

\begin{tabular}{ll}
\hline Become the patient & Workforce (Percentage) \\
\hline Hospitalized & $12(46.15 \%)$ \\
Not specified & $9(34.61 \%)$ \\
Died & $5(19.23 \%)$ \\
Total & $26(100 \%)$ \\
\hline
\end{tabular}

\section{Comments and discussion}

\section{Strength of the study}

Our study allowed us to take stock of primary bronchopulmonary cancers.

\section{Study limit}

The retrospective nature of the study has been the basis of some shortcomings, including some incomplete files that do not contain the information we are interested in. In total, in 5 years out of 386 fibroscopies performed, we have collected 26 cases of primary bronchopulmonary cancers, ie $6.68 \%$. This prevalence is comparable to that of M'Boussa et al., ${ }^{7}$ in Brazzaville in 1990, which reported $8.5 \%$ of primary bronchopulmonary cancers on 200 fibroscopies performed in 5 years $^{7}$ and is lower than that of Boguikouma et al., ${ }^{4}$ which reported $12.7 \%$ of primary bronchopulmonary cancers on 550 bronchoscopies performed. ${ }^{4}$ This could be explained by smoking in Gabon $75 \%$ of the cases, whereas in our study smoking was found only in $20.83 \%$ of the cases all men. Thus, several epidemiological studies have shown the major role of cigarette smoke in the development of this cancer. ${ }^{8,9}$ Female smoking is recent and is at a very low rate in Africa, ${ }^{10}$ hence the absence of smoking among women in our study, which is confirmed by several African studies, notably by Niang et al. ${ }^{11}$, Keita et al., ${ }^{12}$ and Ouedraogo et al. ${ }^{13}$ The average age of patients was 56.65 years (range between 35 and 83 years) in our study, which is comparable with the results of numerous studies in Africa. ${ }^{4,14,15}$ In our study $73.07 \%$ of the patients were men with a sex ratio of 2.71 . These findings are consistent with those of Keita et al., ${ }^{12}$ and Domoua et al. ${ }^{6}$, which found $78.84 \%$ and $79.2 \%$ respectively. ${ }^{12,16}$ In our work, chest pain and cough were the most frequent functional signs with $76.92 \%$ of cases each. These findings are consistent with Keita et al., ${ }^{12}$ findings of $71 \%$ and $67 \%$, respectively. ${ }^{12}$ Emaciation and alteration of general state were found in $65.38 \%$ and $50 \%$, respectively, which may account for the late consultation of more than half of our patients $(68.41 \%)$ at a locally advanced and disseminated stage. Patients with pleurisy were the most frequent associated clinical manifestations, $34.61 \%$ of cases, the result being identical to that of Keita et al. ${ }^{12}$, who had recovered $34.61 \% .^{12}$

In the course of our study, we found a delay in diagnosis related to an advanced stage of the disease to which the patient consults in the hospital, and $68.41 \%$ of our patients had consulted at a locally advanced and disseminated stage; on the other hand, a long waiting time for the anatomopathological result which was 24.69 days (extremes between 7 and 67 days), this may be explained by the insufficiency of the technical platform and the staff of the anatomycytopathology department. The latter is the only laboratory responsible for the pathological examination of all surgical specimens and specimens from Togo. Patients with pleurisy had a greater frequency of chest xrays ( $26.31 \%$ of the cases), followed by atelectasis $(21.05 \%$ of the cases), this being explained by the fact that our patients had been seen in the late stage III and IV of their disease). In $88.46 \%$ (23 patients) of the cases, it was bronchial fibroscopy that allowed us to confirm the diagnosis. The latter was confirmed by pleural, pulmonary and axillary lymph node biopsy in 3 patients (11.54\%). Thus, the introduction of bronchial fibroscopy into the practice of pneumologists in Africa has fundamentally improved the diagnostic approach of primary bronchopulmonary cancer. ${ }^{13,17}$ Squamous cell carcinoma was the most frequent histologic type (30.76\%) followed by small cell carcinoma (26.92\%) and adenocarcinoma (15.38\%). These results are similar to those of Ouedraogo et al., ${ }^{13}$ in Burkina Faso, which found squamous cell carcinoma $46.8 \%$ and small cell carcinoma $18.7 \%$, respectively, as the most frequent histological types. Therapeutic management was based on palliative care $(88.47 \%)$ and chemotherapy (11.53\%). None of the operable patients had undergone surgery, this could be explained by the absence of a thoracic surgeon in Togo and/or the high cost of surgery which is not accessible to most of the population. Of the 7 patients with small cell cancer, only 3 were able to benefit from chemotherapy, this could be explained by the high cost of chemotherapy. Thus, in Morocco, Jabri et al. ${ }^{18}$ found $42.5 \%$ of palliative care, which could be explained by a more efficient technical plateau in the Maghreb in the management of bronchopulmonary cancers. ${ }^{18}$ In our study we have 5 deaths $(19.23 \%)$, and $21(80.77 \%)$ patients whose evolutionary follow-up was not specified, this can be explained by the delay in the diagnosis, the absence of therapeutic means and the severity of CBPs whose survival in 5 years does not exceed $19 \% .^{3}$

\section{Conclusion}

Improved management of primary bronchopulmonary cancers in the service is primarily through tobacco control, thoracic surgery training and multidisciplinary consultation meetings. The introduction of fiberoptic bronchoscopy has also made the diagnosis more accurate, easier and perhaps if used earlier in the management of patients may improve outcomes prospectively. 


\section{Acknowledgments}

None.

\section{Conflicts of interest}

Authors declare that there is no conflict of interest.

\section{References}

1. Remontel L, Esteve J, Bouvier AM, et al. Cancer incidence and mortality in France over the period 1978-2000. Rev epidemiol sante publique. 2003;51(1):3-10.

2. Parkin DM. Cancer occurence in developping countries. OMS International agency for research on cancer: Lyon, France; 1986.

3. Moro S, Urban, Zalcman, et al. (2010) Lung tumors, primitive and secondary. In College of Pneumology Teachings, Repository for the preparation of ECN; 2010. 1-33 p.

4. Boguikouma JB, Perret JL, Diané C, et al. Bronchial Fibroscopy in Bronchopulmonary Cancer in Gabon. Med Afr Noire. 1991;38(12):825827.

5. Ouedraogo M, Zigani A, Ouedraogo SM, et al. Contribution of bronchial endoscopy in a pulmonology department of a developing country. Rev Mal Respir. 2001;18(3):297-300.

6. Sokpoh HM, Grunitzky Bekele M, et al. Diagnostic contribution of bronchoscopy coupled bronchoscopy: the anatomo-cyto-diagnosis in bronchopulmonary cancers at Lomé University Hospital Center. Med Afr Black. 1994;41:615-619.

7. Mboussa J, Nkanga A, Gantsiala M, et al. Review of 200 bronchial endoscopies at the Brazzaville Hospital Center. Med Afr Black. 1990;37:457-459.
8. Doll R, Hill AB. Mortality in relation to smoking: ten years observations of british doctors. Br Med J. 1964;1(5396):1460-1467.

9. Benhamou S, Benhamou E, Tirmarche M, et al. Lung cancer and use of cigarettes: a french case-control study. J Natl Cancer Inst. 1985;74(6):1169-1175.

10. Nguemby C, Mbina C, Klotz F, et al. Lung cancer in Gabon. Méd d'Afr Noire. 1987;34:951-955.

11. Niang A, Bonnichon A, Ba-Fall K, et al. Bronchial cancer in Senegal. Med Trop. 2007;67(6):651-656.

12. Keita B, Konandji MM, Sangare S. Primary Bronchial Cancer in the MiddleHospital Specialized In Bamako. Méd Afr Noire. 1992;39(11):765-768.

13. Ouedrago M, Boncoungou K, Ouedrago SM, et al. Bronchopulmonary Cancers at Yalgado Ouedrago Teaching Hospital: Epidemiological and Clinical Aspects. Rev of Tropical Pneumology. 2008;10:29-32.

14. Kuaban C, Essame Oyono JL, Afaneze E, et al. Primary lung cancers in Gabon. Méd Afr Noire. 1994;41:165-168.

15. Mboussa J. Lung cancer in Congo: Epidemiological aspects. Méd Afr Noire. 1994;38:369-371.

16. Domoua K, Eholie S, Coulibaly C, et al. Contribution of bronchial fibroscopy in the diagnosis of primary bronchial cancers in Abidjan-Cote d'Ivoire. Med Afr Black. 1998;45:163-165.

17. Kao TP. Contribution of bronchial fibroscopy to the diagnosis of bronchopulmonary disorders in the Pneumo-phthisiology department of the Lomé University Hospital. About 95 cases. University of Lomé: Togo; 1983.

18. Jabri L, Zamiati S, Trombati N, et al. Diagnostic performance of fibroscopic specimens in bronchopulmonary cancers. Maghreb Medical. 1999;332:8-10. 